\title{
THE EFFECTS OF COMBINED NERVE RESECTION AND CAVITY PREPARATION AND RESTORATION ON RESPONSE DENTINE FORMATION IN RABBIT INCISORS
}

\author{
J. K. Avery, C. F. Cox and R. E. Corpron \\ Oral Histology Laboratory, Department of Oral Biology, Ihe University of Michigan, School of Dentistry, \\ Ann Arbor, Michigan 48104, U.S.A.
}

\begin{abstract}
Summary-This study was carried out to determine the effects of nerve resection and cavity preparation with restoration (CPR) on the formation of response dentine in continually developing rabbit incisor teeth. Resections of the inferior alveolar nerve (IAN) and/or the superior cervical ganglion ( $S C G$ ) were performed on the right side of 42 adult New Zealand rabbits. Fifteen days were allowed for neural degeneration, after which uniform CPR were placed in both resected and adjacent normal incisors. Half of the operated animals were killed 14 days after CPR placement and the second half, 35 days after. Both radiographic and histological evidence revealed a dramatic increase in dentine deposition following IAN and IAN-SCG with CPR both 14 and 35 days after cavity preparation. The pulps of these neural-resected and CPR incisors were small and limited to the growing end of the tooth. Most of the newly formed dentine appeared regular and without defects; however, the dentine found at the apex was distorted with the appearance of osteodentine. At 14 and 35 days after CPR, the SCG-resected incisors showed no more response dentine formation than adjacent non-resected teeth. Radiographic and histologic appearance of CPR treated incisors indicated they were comparable in size and morphology to the controls.
\end{abstract}

Rescetion of the nerve supply to a continuously developing incisor produces varying effects which appear dependent upon whether the somatic or autonomic nerve supply to the tooth is interrupted. The most frequently reported effect of the sensory or inferior alveolar nerve (IAN) resection is an increased rate of tooth eruption (Edwards and Kitchen, 1938; Rehak, 1963); however, this effect was not observed after sympathetic resection (Leist, 1927; Taylor and Butcher, 1951).

Bishop and Dorman (1963) reported that stimulation of the superior cervical ganglion caused vasoconstriction of the mandibular artery, while sectioning of the somatic alveolar nerve resulted in an increased blood flow in this artery. Weatherred (1965) stimulated the peripherally distal cut end of the inferior alveolar nerve and recorded an increase in intrapulpal pressure. However, stimulation of the cervical sympathetic ganglion caused a decrease in the recorded pulpal pressure. Avery et al. (1971) observed vasodilation of pulpal vessels in rabbit incisors following cervical sympathectomy. In this same study, 14 days after IAN resection, the loss of many of the fine peripheral branches as well as the larger, centrally located trunks in the pulp chambers of rabbit incisors was noted.

Butcher and Taylor (1951) noted continued normal incisor development after resection of the inferior alveolar nerve in the rat, but Rehak (1963) reported bizarre dentinal changes which included the formation of ostcodentine with entrapped odontoblasts, widened predentine, globular dentine and irregular patterns of calcification in the rat incisor following inferior alveolar nerve resection. Weatherred, Kroeger and Smith (1963) found that irregular and defective dentine were present in the oldest area of the tooth after somatic nerve resection, but observed only slight alterations in the incremental pattern of dentine formation at the growing end. Using a similar approach in the rabbit, Avery et al. (1971) noted gnarled and irregular dentine deposition in the incisal third of the incisor tip accompanied by a minute opening of the incisal canal into the oral cavity at the tips of the teeth following resection of the inferior alveolar nerve, and a combination of the inferior alveolar and superior cervical ganglion.

Dentinal deposition in most mammals occurs in an appositional manner throughout life. The dentine formed initially is termed "primary" dentine and that formed later in life, which may be somewhat altered in structure, "secondary" dentine (Provenza, 1964; Sicher and Bhaskar, 1972). Secondary dentine continues formation along the entire pulp-dentinal surface throughout life.

In contrast to the slow incremental circumpulpal deposition of primary and secondary dentine, "reparative dentine" (James and Schour, 1950; Bhaskar et al., 1969; Sicher and Bhaskar, 1972; "tertiary", Kuttler, 1959) is believed to be a localized defensive response 
by the pulp which deposits dentine at specific sites in response to dentinal irritation, although the mechanism controlling its formation is unknown. Since it is recognized that an innervated tooth maintains the potential for a reparative dentinal response to injurious stimulation, it was the purpose of this study to learn the effects on dental pulp of denervated teeth in the rabbit by cavity preparation.

\section{MATERIALS AND METHODS}

The continuously growing mandibular incisors of New Zealand white rabbits as reported in previous studies (Avery et al., 1971) were used to study the effects of neural resection and dentine stimulation by cavity preparation and restoration (CPR) on dentine formation. A total of 46 animals was used, each weighing between 20 and $40 \mathrm{~kg}$. In 42 animals, equal groups (14 per group) of inferior alveolar nerve (IAN), superior cervical ganglion (SCG) or combined inferior alveolar nerve-superior cervical ganglion (COMB) resections were performed on the right side of the jaw. Four additional animals were used, two serving as normal controls and two receiving CPR's in both mandibular and maxillary incisors. In addition, 27 animals were considered which had IAN, SCG and COMB resections. The results of resections alone were reported earlier (Avery et al., 1971), and these results will be referred to in the findings.

All animals were anaesthetized with a $1 \cdot 5 \cdot 2 \cdot 0 \mathrm{ml}$ solution of sodium pentobarbital, $(50 \mathrm{mg} / \mathrm{ml})$ diluted $1: 1$ with 0.9 per cent sterile saline administered via the marginal vein of the ear. Additional anaesthesia was administered intraperiotoneally as needed. The IAN was resected as it approached the mandibular foramen and the proximal stump was sutured to the adjacent pterygoid muscle. The SCG was located by dissection of the carotid sheath in the region of the trachea. The ganglion and a portion of the ascending trunk was removed. The above resection techniques have been more fully elaborated in a previous investigation (Avery et al., 1971).

Allowing 15 days for degeneration of pulpal nerves, labially positioned cavities were prepared in both the left control and right resected incisors. The cavities were situated at the free gingival margin and extended in an apico-pulpal direction. Each cavity was cut in the labial surface of the incisors in the size and shape of the cutting head of a plain tapered fissure bur. They were placed in the long axis of the tooth parallel to the pulp to a uniform depth of $4.5 \mathrm{~mm}$. High speed and water spray coolant were utilized during preparation. The cavities were flushed with water, dried and filled with silver amalgam. Fourteen days after the placement of CPRs, the first series of 23 animals, seven from each IAN, SCG and COMB group, plus control and CPR were killed by left ventricular perfusion with a 10 per cent phosphate buffered formalin. The second series of 23 animals were killed 35 days after CPR. Radiographs were taken to aid in the observation of changes in calcified tissues using bite wing films. All soft tissues as well as the inferior border of compact bone below the second mandibular molar were then removed and the mandibles were allowed further fixation in 10 per cent phosphate buffered formalin for $72 \mathrm{hr}$ at $4^{\circ} \mathrm{C}$. The jaws were then decalcificd with formic acid, embedded in Paraplast, and serially sectioned at $12-18 \mu \mathrm{m}$. Morphological observation of the tissues was carried out using three stains, each stain being repeated every third slide. A standard haematoxylin and eosin stain plus two silver stains were employed with Rowles silver stain providing a controlled differentiation of impregnation of nerve fibres (Rowles and Brain. 1960; Holmes, 1943). Differentiation was controlled by repeated staining with a S-collidine buffer system which intensified the existing stain and toned the background staining.

Eruption data were also collected in this study using both physical measurements and photographs. Due to the great volume of information gathered, these eruption results will be published separately. However, brief comments will be made where necessary within the framework of this paper.

\section{RESULTS}

The normal, continuously growing rabbit incisor is a curved, conical-shaped tooth morphologically similar to the rodent incisor. The apical end of these incisors is the site of differentiation and the region where initiation of odontogenesis occurs. This tooth in its supporting bone has its growing base anterior to the molar teeth. The conical-shaped, radiolucent pulp chamber can be visualized as bounded above and below by dentine which, due to continued deposition, obliterates the pulp chamber near the incisal tip. At the base of the incisor, blood vessels and nerves enter the tooth (Fig. 1). A histologic section of the normal mandibular incisor revealed the pulp to be evenly distributed throughout this area bounded both by dentine and the stellate reticulum (SR), a part of the enamel organ of the tooth. The stellate reticulum appeared only on the labial surface of the incisor and enamel bordering the labial surface of the incisor appeared as a slightly more radiodense region than the dentine (Fig. 2).

Fourteen days after IAN, the histologic appearance of the growing end of the resected incisors (Fig. 3) appeared similar to the normal controls (Fig. 1). Radiographically, the pulp chamber (Fig. 4) appeared similar in size to the normal incisors (Fig. 2). Again at 35 days after CPR. the growing end of these nonresected incisors (Fig. 5) closely resembled those of normal incisors of the same age. Radiographs of the pulpal region indicated no difference in the volume of the pulp in the normal (Fig. 2) and 35 day CPR incisors (Fig. 6).

In the next series of teeth, IAN resection had been followed 15 days later by CPR. Fourteen days after CPR, a considerable amount of dentine had formed in 
the apical region of these incisors (Fig. 19). In addition, the dentine appeared to be buckled at the apical end and distorted along its outer and inner surfaces. Although the pulp appeared very similar histologically to the adjacent nonresected control with CPR, the overall pulpal size was limited by excessive dentine formation. The columnar ameloblastic cell row was absent in some instances and distorted in others. The stellate reticulum and remainder of the enamel organ were severely distorted, and followed the bends in the dentine. Radiographically, the pulp chamber of IAN resected incisors at 14 days appeared markedly reduced in size and was limited to the apical portion of the tooth. These incisors appeared as nearly solid calcified rods with the exception of small, apically located pulp chambers. The enamel was chalky white with a rough and pitted surface when compared to the adjacent glossy and normally pigmented control incisor with CPR.

SCG resected incisors examined 14 days after CPR had pulp chambers which were similar to those in adjacent nonresected incisors (Fig. 19). Both the left and right incisors with CPR appeared to have a similar pulp volume. Examination of the histologic sections revealed normal appearing rows of columnar odontoblasts and ameloblasts which produced regular increments of dentine and enamel. Loss of the fine nerve fibres occurred along the larger blood vessel walls of the SCG-resected incisors as reported earlier (Avery et al., 1971). However, there was no apparent alteration of the larger myelinated sensory trunks and their branches. The enamel appeared overall to be smooth and normally pigmented. Thus, at 14 days after SCG resection, there was little alteration in size or morphology of the pulp (Fig. 19) nor in the amount or quality of dentine and enamel.

Fourteen days following CPR, changes in the pulp and dentine in the COMB-resected incisors were similar to those observed following IAN resection (Fig. 19). The pulp chambers appeared to be reduced in size (Fig. 19) and the dentine was much thicker than in adjacent incisors with CPR. The enamel-formative cells and other parts of the enamel organ were also distorted. In some cases, the enamel was missing near the apical region of the tooth. There was loss of the larger myelinated and smaller nonmyelinated nerves of the pulp of the COMB-resected teeth.

Histologic and radiographic observations of IAN, resected incisors 35 days after CPR (Figs. 7 and 8 ) were similar to those noted at 14 days (Fig. 19). The pulp chamber was further reduced in size due to an increased amount of dentine displacing much of the pulp chamber (Fig. 7). The dentine near the apical end appeared buckled, with few ameloblasts and little or no enamel. A radiograph of an IAN resected incisor at 35 days illustrates the reduced volume of the pulp (Fig. 8) as compared to an unresected incisor with CPR alone (Fig. 6). The enamel appeared overall irregular, pitted and grayish-white.

The pulps of SCG-resected incisors 35 days after CPR
(Fig. 9) appeared normal without any overall distortion of the pulpal cells or vascular networks. A normal amount of dentine was deposited in regular increments and the cell population of the pulp appeared normal. An absence of nerves along the blood vessels was noted. The enamel organ, including the ameloblasts and stellate reticulum seen on the labial aspect of the tooth, appeared normal. A radiograph of an SCGresected incisor 35 days after CPR (Fig. 10) revealed it to be very similar to the adjacent nonresected incisor with a 35 day CPR (Fig. 6). The enamel appeared as a thin radiodense line along the inferior aspect of the SCG-resected incisor. Enamel observed was normal in colour and texture.

Thirty-five days after CPR, COMB resected incisors (Figs. 11 and 12) appeared similar to those which had undergone IAN resection alone (Fig. 19). The pulp chamber appeared limited to the apical growing end of the tooth and the dentine was distorted and enfolded upon itself. The adjacent enamel organ was distorted and the overall enamel appeared irregular and chalkywhite when compared to the adjacent nonresected control incisor. Moreover, the IAN and COMB resections resulted in dentine and enamel that were more friable and prone to fracture.

Further examination of the apical formative areas in the IAN and COMB-resected incisors revealed the supporting structures of the teeth to be normal in histologic appearance while the dentine and enamelforming areas were extensively affected by resection and CPR. The lingual zone of a COMB and CPR of 35 days demonstrated a conspicuous absence of tubular dentine. An area of pulpal proliferatized cells was evident, however, the dentine-included cells (Fig. 14), suggestive of an osteodentine type material. The cells grouped together in an irregular fashion to suggest a rough, buckled surface. A lingual aspect of dentine at 35 days CPR indicates a rather dramatic increase in circumpulpal dentine (Fig. 16) which includes both tubular and cellular elements. In some instances where buckling of the labial dentine occurred, only a rudimentary enamel organ could be visualized with a complete absence of enamel formation (Fig. 17). In the basal region of some teeth, instead of uniform increments of tubular dentine, an irregular deposit appeared which contained cells. Two areas of dentine, one containing cells in lacunae and the other cell processes in tubules, lay adjacent (Fig. 15). Both types were believed to be formed after the neural resection. A row of columnar odontoblasts was seen along the periphery of the pulp organ bordering the dentine, and it is presumed that the vital processes of these cells lie within this tubular dentine. In some instances, along the area where enamel would have normally formed, masses of cementum or a cementum-like substance were deposited along the outer surface of the dentine (Fig. 18). Adjacent to this cementum deposition were a few columnar-shaped ameloblasts which appeared to have deposited a thin increment of enamel. There seemed to be a complete loss of stellate reticulum 
in some instances (Fig. 17). All of these developmental abnormalities appeared to be limited to the developing tooth as the periodontal ligament fibres and adjacent alveolar forming bone appeared normal (Figs. 13 and $15)$.

It should be mentioned that discrete patterns of eruption rates were altered from neural resection and CPR. These eruption rates varied the most in IAN and COMB-resected models, both with and without CPRs.

A composite diagram (Fig. 19) indicates the effects of various nerve resections with and without cavity preparation. The IAN-CPR (14 and 35 days) resulted in several dramatic changes. There was an increase in circumpulpal dentine deposition which resulted in a size reduction of the pulp chamber from $1 / 2$ to $2 / 3$; as well as histological changes in the apical-proliferation zone. This was characterized by buckling. cellular dentine deposition (Figs. 14, 15, 17 and 18), and hypocalcified enamel with loss of its pigmentation.

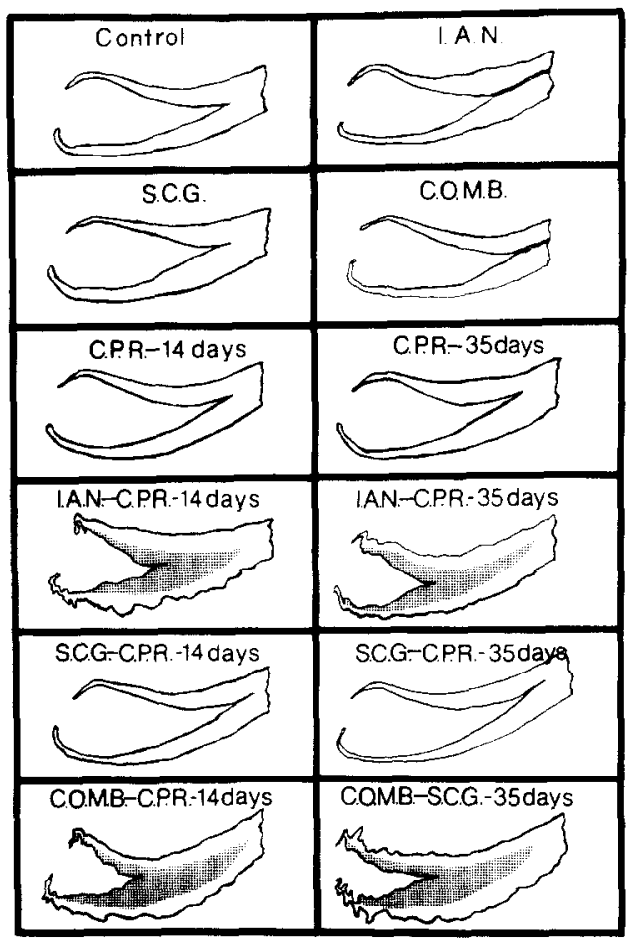

Fig. 19. A composite diagram which illustrates the comparison of the effects of nerve resection, cavity preparation and a combination of both, to a control rabbit incisor. The IAN and COMB nerve resections resulted in the persistance of the incisal canal to the incisal tip. Both the IAN with CPR and COMB with CPR for both 14 and 35 days showed a very dramatic increase in circumpulpal dentine formed, (stippled zone). The labial and lingual proliferative dentine and enamel (labial only) demonstrated buckling which is diagramatically represented. The total reduction in pulp chamber size varied from $1 / 2$ to $2 / 3$ in the specimens considered.

\section{DISCLSSION}

In past studies on denervation of the pulp, there have been varying reports of changes in nerve distribution (Avery et al., 1971), vascular dilation and constriction (Bishop and Dorman, 1963), intrapulpal pressure (Weatherred. 1965) and eruption rates (Taylor and Butcher, 1951: Rehak. 1963). Less attention has been paid to a description of developmental disturbances in teeth resulting from neural resection. Edwards and Kitchen (1938) reported an acceleration in the rate of growth of tooth germs in kittens following SCG removal, but inconsistent results were observed after IAN resection. Rehak (1963) found osteodentine with entrapped odontoblasts, a widened predentine and irregular calcification patterns following IAN resection. Weatherred (1965) resected the IAN in a series of both adult and weanling rats. In adult incisors, he observed structural changes and an increase in growth rate following CPR alone. It is possible that the localized more severe response which resulted in impaired dentine formation. The abnormal dentine contained cellular inclusions, and areas of incomplete calcification were noted. Also. the pulps were exposed at the incisal tips. These findings are similar to those reported in the rabbit following IAN resection by Avery et al. (1971).

Cavity preparation and restoration in human teeth results in reparative or irritation dentine deposited locally underlying the cavity (James and Schour, 1955; Langeland. 1961: Bhaskar et al.. 1969). No notable increase in dentine was observed in the rabbit incisor following CPR alone. It is possible that the localized reparative dentine effect which is deposited under the cavity would. in the continuously growing rodent incisor, have been obscured by additional circumpulpal dentine deposition during continuous eruption of the teeth. Shorter intervals of examination than 14 days following CPR used in this study would possibly have revealed such a localized response.

The effects of stimulation by CPR following IANresection greatly altered development as noted by exuherant circumpulpal dentinal formation which significantly reduced the size of the pulpal chamber by 35 days following CPR (Fig. 11). Moreover, the quality of this dentine appeared abnormal in structure. Some of it contained cells and it appeared buckled and bent at the apical region (Figs. 14, 15, 16 and 17). No openings of the pulp to the exterior were found as had been noted previously by Weatherred (1965) and A very et $\mathrm{al}$. 11971 after IAN-resection alone. From this information it appears that the inferior alveolar nerve exerts a unique form of control over dentine formation in the continuously growing rabbit incisor since innervation by this nerve was the factor lacking when excessive and abnormal formation of dentine occurred following CPR.

An appropriate term is needed to describe the response of the IAN-resected pulp after CPR. Reparative dentine (James and Schour. 1955; Bhaskar et al.. 1969; Baum. 1964: Sicher and Bhaskar, 1972), irregular secondary dentine (Provenza. 1964: Philippas and 
Applebaum, 1968) or irritation dentine (Langeland, 1961; Mjor, 1963; Fisher, El-Kafrawy and Mitchell, 1970) have been used to describe the localized dentine deposition underlying a cavity or an area of dental caries or erosion. The dentinal response observed in the present study following IAN and COMB resection with CPR appeared as a generalized, rather than a localized response. The term "response dentine" is proposed to distinguish this dentinal deposition from a more specialized response.

The observation of altered enamel following denervation and C $P R$ is also of interest. This alteration in enamel was observed 14 days after CPR in the present study. The question arises whether this was a result of the underlying defective dentine development. Weatherred (1965) concluded that the enamel organ may exert a beneficial influence on dentine formation as the least defective dentine was observed underlying the labial enamel. Labial dentine in the present study, however, was seen to be adversely affected similar to the lingual dentine (Figs. 17 and 18). Moreover, the enamel itself in many instances showed defective development. The question remains whether the defective dentine led to. or resulted from. the formation of defective enamel. In some teeth (Fig. 17), it was observed that the enamel organ appeared altered in the cervical loop area. a zone in which ameloblasts have not differentiated and not yet formed enamel. Resection of the IAN without CPR resulted in a loss of pigmentation in the rabbit incisor noted in both the present and an earlier investigation (Avery et al., 1971). Weatherred $(1965)$ reported this change in enamel after IAN resection in the rat. Additionally, the enamel in the present study showed pitting and areas of enamel replacement by cellular cementum. It appeared that the effects of CPR accentuated the effects of IAN resection, and that CPR alone did not affect the development of enamel.

Some investigations have concluded that the effect ol SCG destruction resulted in increased growth rates of the teeth (Edwards and Kitchen, 1938). The present collateral eruption study, indicated an alteration in eruption rates of IAN and COMB which were accentuated with CPR. The histologic and radiographic appearance of SCG-resected with CPR-treated rabbit incisors, however, revealed no significant histological changes of enamel or dentine formation from the normal or CPR incisor.

The most important issue seems to be the obvious relationship of the presence of IAN innervation and hard tissue devclopment. IAN denervation resulted in increased odontoblast and altered ameloblast activity. This was shown by deposition of normal and abnormal dentine and defective enamel. It is unknown whether this occurs by direct or indirect effect of the nerve supply. CPR is seen to accentuate this effect. It has been shown that the odontoblasts have a close relationship to peripheral nerves of the pulp and in the dentine (Corpron, Avery and Cox, 1972). It remains to determine what the nature of this relationship may be.
Acknowledgement-This project was supported by U.S.P.H.S. Research Grant DE 01604 from the National Institute of Dental Research, National Institutes of Health, Bethesda, Maryland.

\section{REFERENCES}

Avery J. K., Strachan D. S., Corpron R. E. and Cox C. F. 1971. Morphological studies of the altered pulps of the New Zealand white rabbit after resection of the inferior alveolar nerve and/or the superior cervical ganglion. Anat. Rec. 171, 495508.

Baume L. J. 1964. Survey of dentine biology. Brit. De'nt. Jour. 116, 254-259.

Bhaskar S. N.. Cutright D. E., Beasley J. D. and Boyers R. C. 1969. Pulpal response to four restorative materials. Oral Surg.. 28, 126-133.

Bishop I. G. and Dorman H. L. 1963. Changes in perfusion pressure in the mandibular artery induced by functional alterations of the superior cervical ganglion. $J$ dent. Re's. 42, 777-782.

Butcher E. D. and Taylor A. C. 1951. The effects of denervation and ischemia upon the teeth of the monkey. J. dent. Res. 30, 365-275.

Corpron R. E., A very J. K. and Cox C. F. 1972. Litrastructure of intradentinal nerves after resection of the inferior alveolar nerve. J. dent. Res. 51, 673.

Edwards L. F. and Kitchen P. C. 1938. Does resection of nerves supplying the mandible affect development of teeth? J. dent. Res. 17, 115-124.

Fisher F. M., El-Kafrawy A. and Mitchell D. F. 1970. Studies of tertiary dentin in monkey teeth using vital dyes. J. dent. Res. 49, 1537-1540.

Holmes W. 1943. Silver staining of nerve axons in paraffin sections. Anat. Re'c. 86, 157-187.

James V. E. and Schour I. 1955. Early dentinal and pulpal changes following cavity preparations and filling materials in dogs. Oral Surg., 8, 1305-1314.

Kuttler Y. 1959. Classification of dentine into primary, secondary and tertiary. Oral Surg.. 12, 996 1001.

Langeland K. 1961. Effects of various procedures on the human dental pulp. Oral Surg. 14, 210-233.

Leist M. 1927. Uber den Einfluss des vegentatiuen Neruensystems auf die Zahne. Z. Stomat. 25, 765.771.

Mjor I. A. 1963. The effect of calcium hydroxide, zinc oxideeugenol and amalgam on the pulp. Odontologisk Tidskrift 71, pp. 94 105.

Philippas G. G. and Applebaum E. 1968. Location of irregular secondary dentin formation. J. dent. Res. 47, 769-778.

Provenza D. V. 1964 . Oral Histology. pp. 245-246. J. B. Lippincott Co., Philadelphia

Rehak J. R. 1963. Course and resection of the inferior alveolar nerves in rats. $J . d e n t$. Res. 42, $1159-1168$.

Rowles S. L. and Brain E. B. 1960. Improved silver method for staining nerve fibres in decalcified sections of teeth Archs oral Biol. 2, $64-68$.

Sicher H. and Bhaskar S. N. 1972. Orhan's Ora' Histology and Embryology. 7th edition p. 116. The C. V. Mosby Company, Saint Louis.

Taylor A. C. and Butcher E. O. 1951. The regulation of eruption rate in the incisor teeth of the white rat. J. Exp. Zool. 117, 165-188. 
Weatherred J. G., Kroeger D. C. and Smith E. L. 1963. Pressure response in the dental pulp chamber to inferior alveolar nerve stimulation. Federation Proc. 22, 287.
Weatherred J. G. 1965. Peripheral nervous system effects in the dental pulp of the rat and dog. Thesis, University of Texas

Résumé--Cette étude cst destinće à détcrminer les cffets de la réscetion nerveuse ct de la préparation de cavité, suivie d'obturation (CPR), sur la formation de la dentine réactionnelle au niveau de l'incisive de lapin, en voie de développement. Les résections du nerf dentaire inférieur (IAN) et/ou du ganglion cervical supérieur (SCG) ont été réalisées du côté droit de 42 lapins néozélandais adultes. Après 15 jours d'attente pour obtenir une dégénérescence nerveuse, des CPR sont placés dans les incisives réséquées et les incisives adjacentes normales. La moitié (21) des aninlaux opérés sont sacrifiés 14 jours après la mise en place du CPR el la secondé Invilié (21), 35 jours après. A la fois, la radiographie et l'histologie montrent une augmentation spectaculaire de la formation de la dentine après IAN et IAN-SCG, avec CPR, à la fois 14 et 35 jours après préparation de cavités. Les pulpes de ces incisives, ayant subi une résection nerveuse et un CPR, sont étroites et limitées à l'extrémité en croissance de la dent. La plupart de la dentine néoformée apparait régulière, sans défauts structuraux, cependant la dentine apicale est perturbée par l'apparition d'ostéodentine. Après 14 et 35 jours de CPR, les incisives ayant subi une SCG ne présentent pas une formation dentinaire augmentée par rapport aux dents adjacentes non réséquées. L'aspect radiographique et histologique d'incisives traitées au CPR indiquent qu'elles sont identiques en taille et en morphologie aux dents témoins.

Zusammenfassung - In dieser Untersuchung sollten die Auswirkungen der Nervenresektion und der Kavitätenpräparation und -füllung (CPR) auf die Entwicklung von Reizdentin in den kontinuierlich wachsenden Schneidezähnen von Kaninchen festgestellt werden. Resektionen des $N$. mandibularis (IAN) und/oder des oberen Halsganglions (SCG) wurden bei 42 ausgewachsenen Neuseeland-Kaninchen rechsseitig ausgeführt. Nach einer 15 tägigen Pause zur neuralen Degeneration wurden in den resezierten und in den benachbarten normalen Schneidezähnen gleichgeformte Kavitäten und Füllungen angebracht. Die Hälfte der operierten Tiere (21) wurde 14 Tage nach Kavitätenfüllung, die zweite Hälfte (21) 35 Tage nach den Füllungen getötet. Radiographien und histologische Befunde ergaben sowohl 14 als auch 35 Tage nach Kavitätenpräparation eine erheblich gesteigerte Dentinablagerung nach IAN und IAN-SCG mit CPR. Die Pulpen dieser nervenresezierten und gefüllten Schneidezähne waren schmal und auf das Wachstumsende des Zahnes begrenzt. Der größte Teil des neugebildeten Dentins erschien regulär und ohne Defekte. jedoch war das am A pex beobachtete Dentin unregelmäßig und ähnelte dem Osteodentin. Zum Zeitpunkt 14 und 35 Tage nach CPR wiesen die SCG-resezierten Schneidezähne nicht mehr Reizdentinbildung als die benachbarten nichtresezierten Zähne auf. Radiographische und histologische Befunde der CPR-behandelten Schneidezähne deuteten darauf hin, daß sic in Große und Morphologie mit den Kontrollen vergleichbar waren. 
Plates 1-3 Overleaf 


\section{Plati: 1}

Fig. 1. A longitudinal section through the apical odontogenic zone of a normal rabbit mandibular incisor. Above the pulp $(\mathbf{P})$ is the thin band of lingual dentine and below is the layer of labial dentine and enamel bounded below and apically by stellate reticulum (SR). Thin vascular channels course in a longitudinal direction through the apical pulp tissue. Haematoxylin and eosin. $\times 10$

Fig. 2. A radiograph of the normal mandibular incisor seen in Fig. 2. The conical pulp is widest at the apex tapering into the substance of the incisor. The apex is bounded ahove and helow by extensions of lingual and labial dentine. $\times 4$

Fig. 3. A longitudinal section through a mandibular incisor after IAN resection. No significant changes appear in the pulp morphology as compared to the normal incisor (Fig. 2). Haematoxylin and eosin. $\times 10$

Fig. 4. A radiograph of the incisor viewed in Fig. 4 at 14 days following IAN. The conical radiolucent pulp zone is similar to that in the normal tooth seen in Fig. 3. $\times 4$

Fig. 5. A longitudinal section through the apical area of an incisor 35 days after CPR. No alterations in pulp morphology or of the odontogenic zones are evident. Haematoxylin and eosin. $\times 10$

Fig. 6. A radiograph of the incisor viewed in Fig. 6. There is no resultant change to the pulp chamber volume, compared to Fig. 3. nor are there changes to the labial and longial dentine-forming zones. $\times 4$ 


\section{Neural resection and response dentine formation}

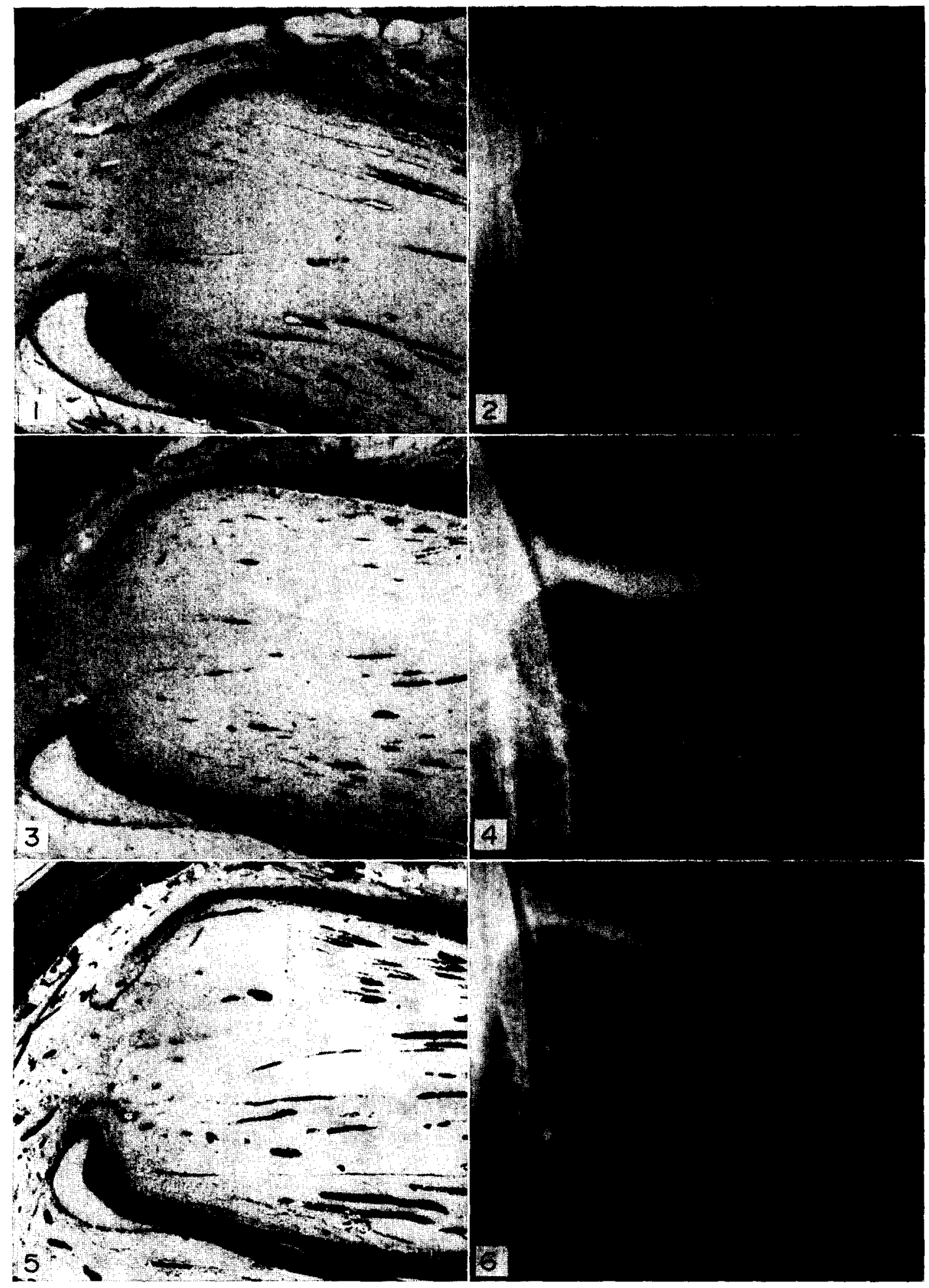

Plate 1

A.O.B. f.p. 546 


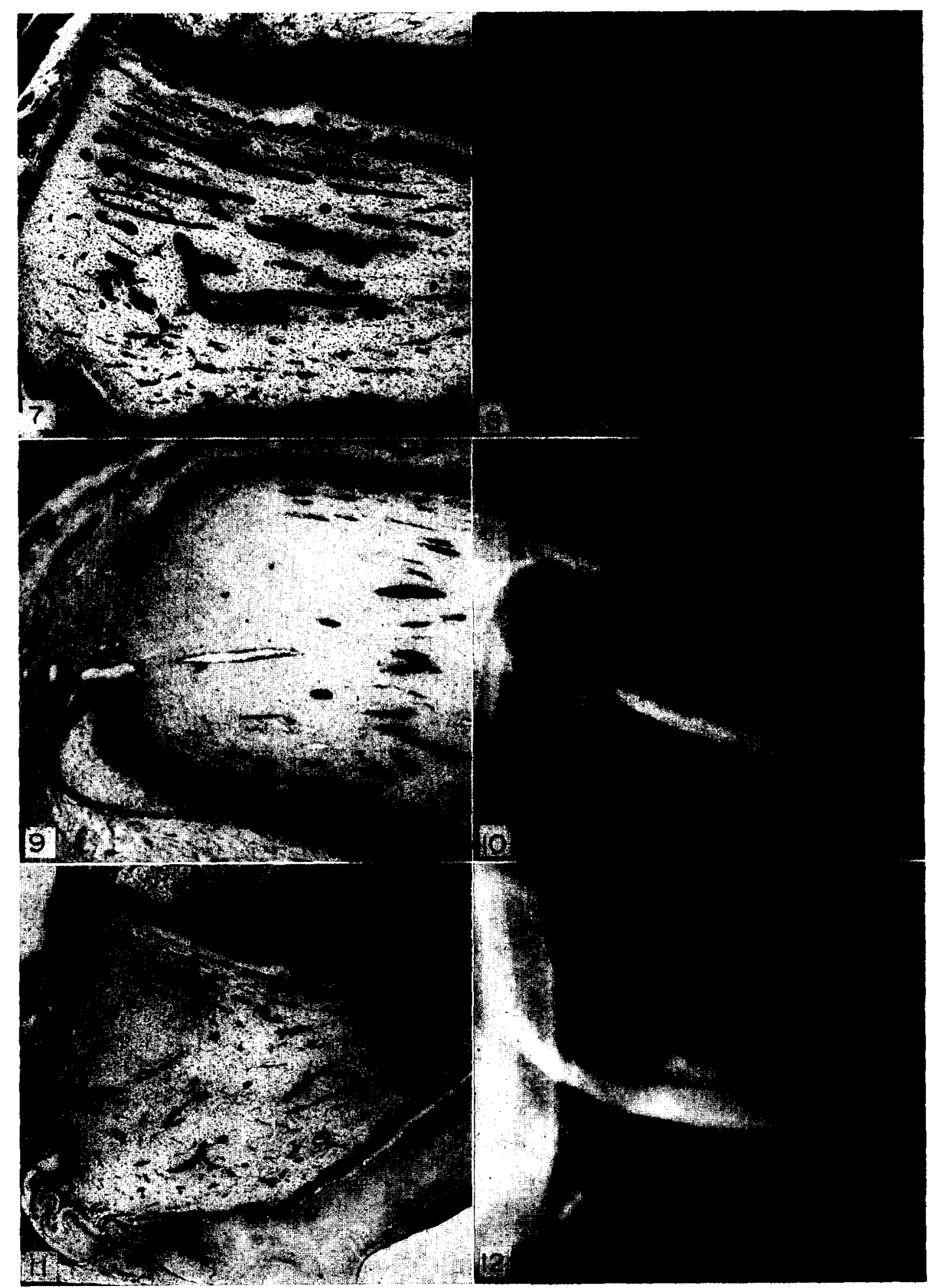

Plate 2 


\section{Plate: 2}

Fig. 7. A longitudinal section of the apical zone of an IAN-resected incisor 35 days after CPR. The pulp chamber is smaller in size than the IAN incisor (Fig. 4). There is apparent buckling of both the labial and lingual dentine. The pulp cells appear to be either crowded or increased in number at the apex, with a noted prominence of blood vessels which may be due to the increased circumpulpal dentine. Haematoxylin and eosin. $\times 10$

Fig. 8. A radiograph of an IAN-resected incisor 35 days after CPR which confirms the diminished size of the pulp. Buckling of the labial-apical dentine can also be observed. $\times 4$

Fig. 9. A longitudinal section of an SCG-resected incisor 35 days after CPR. No alteration in pulpal morphology including the odontogenic zones can be seen when this section is compared to the pulp 35 days after CPR (Fig. 6). Haematoxylin and eosin. $\times 10$

Fig. 10. A radiograph of an SCG-resected incisor 35 days after CPR. The size of the pulp chamber as indicated by the conical radioluecnt area appears comparable to the radiograph of a control incisor (Fig. 3). $\times 4$

Fig. 11. A longitudinal section of the apical zone of a COMB-resected incisor 35 days after CPR. The pulp chamber is reduced in size when compared to the control CPR incisor after 35 days. The labial dentine is very accentuated with folds or buckles which has also affected the dentine-enamel interface. The enamel organ is not apparent along the labial surface of the dentine. The lingual dentine appears cellular at the apex. Haematoxylin and eosin. $\times 10$

Fig. 12. A radiograph of a COMB-resected incisor 35 days after CPR which confirms the decrease in pulp size seen in Fig. 12. Note the irregularities of the labial enamel and dentine surface. $\times 4$ 
Plate 3

Fig. 13. A section of the lingual dentine of a 14 day CPR incisor following IAN-resection. The odontoblast zone is somewhat disorganized however, the dentine retains its characteristic tubular appearance. The apical proliferative zone of dentine is bent on itself with irregularities seen to the right. The aveolar bone lies above demonstrating a rather irregular surface, with an adjacent periodontal ligament situated between. Haemotoxylin and eosin. $\times 35$

Fig. 14. A section of the lingual apical dentine from a 35 day CPR specimen following a COMB resection. The dentine has lost its typical tubular appearance, being replaced by a cellular material. The buckling is observed here with some disorganization of the adjacent periodontium (PE). A bone spicule may be seen in the upper left. $\times 70$

Fig. 15. A section of the lingual aspect of an COMB-resected incisor 35 days after CPR. The zone of dentine (D) which shows buckling reveals the presence of cells in the matrix (arrows). The dentine on the left which is closer to the apex appears more normal and contains tubules and a row of well-organized odontoblasts. Below is the pulp tissue $(\mathrm{P})$ and above the dentine is periodontal ligament $(\mathrm{PL})$ and alveolar bone. Haematoxylin and eosin. $\times 50$

Fig. 16. A section of the lingual aspect of dentine from a 35 day CPR incisor following COMB resection. This specimen indicates a deposition of circumpulpal dentine. Incremental zones may be seen with a portion of the dentine appearing tubular and the more apical zone showing the inclusion of cells.

The odontoblasts have lost their regular columnar features. Haematoxylin and eosin. $\times 63$

Fig. 17. A section of the labial aspect of an COMB-resected incisor 35 days after CPR. This is a higher magnification of the photograph of the apical end of the incisor shown in Fig. 12. The enamel organ, including the stellate reticulum (SR), is severely distorted. The cervical loop $(\mathrm{CL})$ is seen, upper left. The pulp is seen above (P). There appears a buckling of the dentine and absence of enamel in this area. Note the cellular cementum or osteoid tissue (arrows) that occupies the area where enamel would normally appear. Haematoxylin and cosin. $\times 40$

Fig. 18. A section of the labial aspect of an COMB-resected incisor 35 days after CPR. The pulp is seen above (P) and periodontal ligament (PL) below. Along the inferior surface of the dentine can be seen a thin deposit of enamel below which a row of columnar enamel-forming cells appear (small arrows). These ameloblasts are shorter and indistinct. Merging with this zone is a deposition of either cementum or bone large arrow). Haematoxylin and eosin. $\times 63$ 
Neural resection and response dentine formation

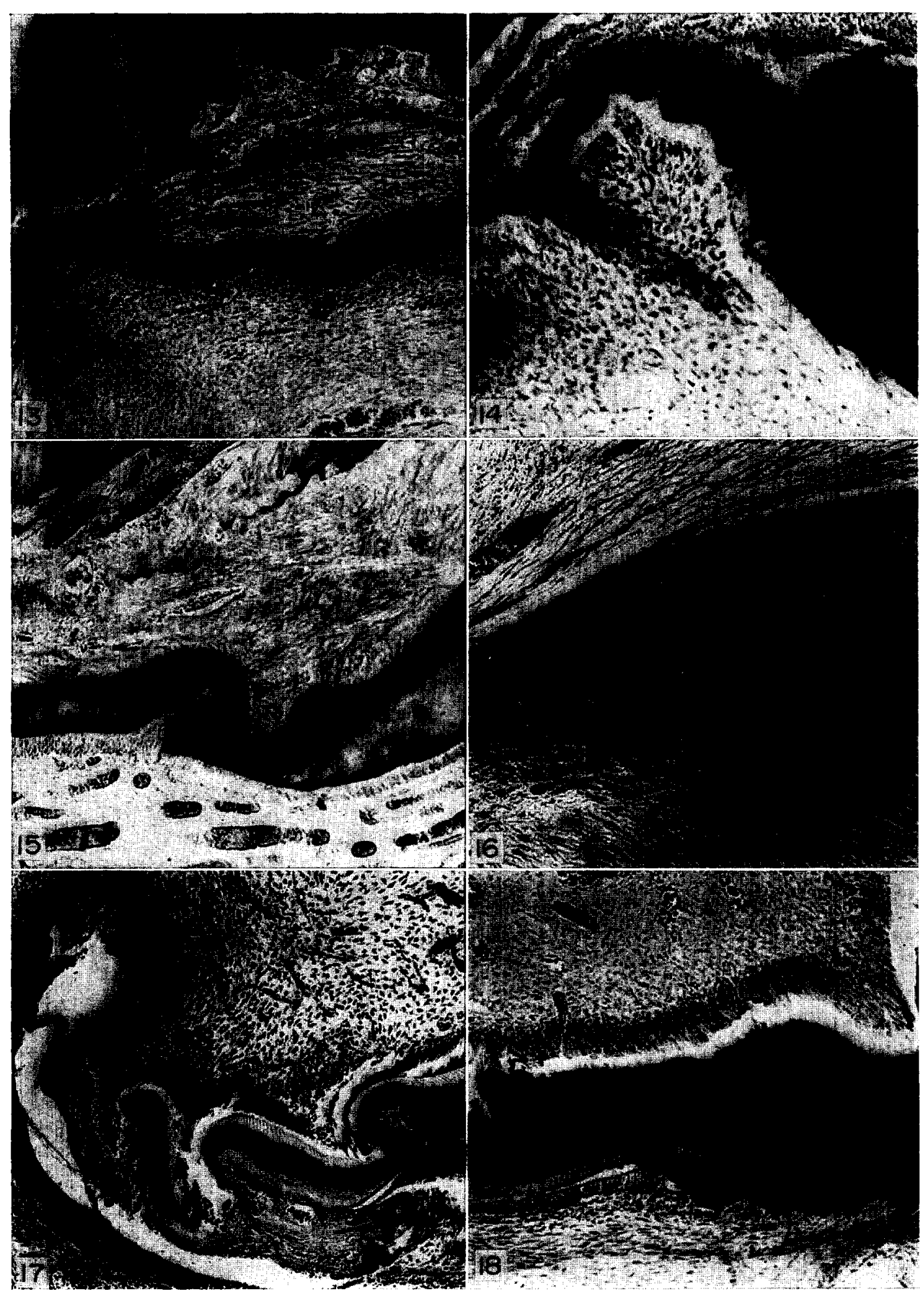

Plate 3 